\title{
Impact of EDDS Dosage on Lead Phytoextraction in Contaminated Urban Residential Soils
}

\section{OPEN ACCESS}

Edited by:

Reto Gieré,

University of Pennsylvania, United States

Reviewed by:

Mohammad Mahmudur Rahman, The University of Newcastle, Australia

Prafulla Kumar Sahoo,

Central University of Punjab, India

Pradip Bhattacharyya,

Indian Statistical Institute, India Matthew Dietrich,

Indiana University, Purdue University Indianapolis, United States

*Correspondence: Dibyendu Sarkar dsarkar@stevens.edu

Specialty section:

This article was submitted to Urban Resource Management, a section of the journal

Frontiers in Sustainable Cities

Received: 09 September 2021 Accepted: 30 November 2021

Published: 04 January 2022

Citation:

Zhang Z, Sarkar D, Sidhu V, Warke M and Datta $R$ (2022) Impact of EDDS Dosage on Lead Phytoextraction in Contaminated Urban Residential Soils. Front. Sustain. Cities 3:773467. doi: 10.3389/frsc.2021.773467

\author{
Zhiming Zhang ${ }^{1}$, Dibyendu Sarkar ${ }^{1 *}$, Virinder Sidhu ${ }^{1}$, Manas Warke ${ }^{2}$ and Rupali Datta ${ }^{2}$ \\ ${ }^{1}$ Department of Civil, Environmental and Ocean Engineering, Stevens Institute of Technology, Hoboken, NJ, United States, \\ ${ }^{2}$ Department of Biological Sciences, Michigan Technological University, Houghton, MI, United States
}

Lead $(\mathrm{Pb})$ contamination in soils of residential properties due to peeling and chipping of $\mathrm{Pb}$-based paint can cause human health problems. Phytoextraction is a green technology that has the potential to remediate soil $\mathrm{Pb}$. The efficiency of phytoextraction is dependent on the geochemical forms of $\mathrm{Pb}$ in soil. A biodegradable chelating agent, ethylenediaminedisuccinic acid (EDDS), was previously shown to enhance Pb removal by facilitating phytoextraction. In this study, EDDS was tested at various concentrations for its potential in mobilizing $\mathrm{Pb}$ in urban residential soils in Jersey City, New Jersey, and San Antonio, Texas. Results show that the concentrations of plant-available forms of $\mathrm{Pb}$ increased with the increasing dosage of EDDS from 2 to $30 \mathrm{mmol} / \mathrm{L}$. The addition of EDDS at $30 \mathrm{mmol} / \mathrm{L}$ resulted in the conversion of up to $61.2 \%$ and $68.9 \%$ of the total $\mathrm{Pb}$ to plant-available forms in Jersey City and San Antonio soils, respectively. Further analysis showed that, after EDDS application, carbonate-bound $\mathrm{Pb}$, oxide-bound $\mathrm{Pb}$, organic-bound $\mathrm{Pb}$, and residual silicate-bound $\mathrm{Pb}$ were transformed to plant-available forms. Higher doses of EDDS performed better than lower doses in transforming soil $\mathrm{Pb}$ forms, especially for the oxide-bound $\mathrm{Pb}$. Strong correlations between $\mathrm{Pb}$ concentrations measured on-site using a portable X-ray Fluorescence Analyzer ( $p$-XRF) and those obtained in the laboratory using Inductively Coupled Plasma-Optical Emission Spectroscopy (ICP-OES) confirmed that $\mathrm{p}-\mathrm{XRF}$ is a reliable rapid, convenient technology to measure $\mathrm{Pb}$ levels in situ.

Keywords: lead-based paint, soil lead contamination, geochemical fractions, plant-available lead, chelating agent, phytoextraction

\section{INTRODUCTION}

Lead $(\mathrm{Pb})$ contamination in soil and water in urban areas is of serious concern, due to its severe impact on human health, especially in children. Studies show that high blood lead levels (BLLs) in children lead to physiological and neurological disorders, and the BLLs are closely related to soil $\mathrm{Pb}$ contamination in inner-city areas (Mielke et al., 1983; Elhelu et al., 1995). Specifically, elevated BLLs can be correlated with Pb levels in yard soils in residential properties (Mielke et al., 1997; Johnson and Bretsch, 2002; Li et al., 2012; Zahran et al., 2013; Laidlaw et al., 2017). Moreover, a decline in BLLs in children was reported to correlate with the decrease of $\mathrm{Pb}$ concentration in topsoil (Mielke et al., 2019). Soil $\mathrm{Pb}$ contamination in residential properties is attributed mainly to the usage of Pb-based paint (McClintock, 2012). Before Pb-based paints were banned by the US Consumer Product Safety Commission in 1978, $\mathrm{Pb}$ minerals were added to paints to improve their durability 
and flexibility (Clark and Knudsen, 2013). Approximately seven million tons of $\mathrm{Pb}$ were used in the US for white paint production during the century (Clark et al., 1991). The deterioration of exterior $\mathrm{Pb}$-based paints could result in much higher soil $\mathrm{Pb}$ concentrations than the US Environmental Protection Agency (USEPA) Pb hazard cutoff value of $400 \mathrm{mg} / \mathrm{kg}$ for soil in children's play areas (USEPA, 2001).

Phytoextraction, a form of phytoremediation that uses green plants to remove metal contaminants from soils, has the potential to be an effective, low-cost, and environment-friendly method for soil $\mathrm{Pb}$ remediation (Alkorta et al., 2004a; Mojiri, 2011). However, the efficiency of phytoextraction is strongly dependent on the existing forms of $\mathrm{Pb}$ in soil, because only soluble and exchangeable forms of $\mathrm{Pb}$ are available for plant uptake (Attinti et al., 2017). Chelating agents can enhance phytoextraction by increasing $\mathrm{Pb}$ solubility and plant uptake (Alkorta et al., 2004b). Although a variety of chelating agents have been reported to be effective, appropriate agents should be carefully chosen based upon their potential toxicity and concomitant damage caused to the environment. The most commonly used and effective chelating agent for metal mobilization is EDTA, which is persistent in the environment due to low biodegradability and can cause metals to leach into the groundwater (Gluhar et al., 2020). Biodegradable chelating agents are preferable, and ethylenediaminedisuccinic acid (EDDS) is one such candidate. Previously we showed that EDDS facilitated $\mathrm{Pb}$ phytoextraction by mobilizing $\mathrm{Pb}$ from paint-contaminated soil in a mesocosm study using vetiver grass (Attinti et al., 2017). The $\mathrm{Pb}$ concentration increased by $53 \%$ and $203 \%$ in vetiver shoots and by $73 \%$ and $84 \%$ in vetiver roots after two rounds of EDDS application, which proved the feasibility of EDDS facilitated phytoremediation. Vetiver grass is a good candidate for $\mathrm{Pb}$ phytoremediation, as it can accumulate high concentrations of $\mathrm{Pb}$ $(\sim 20,000 \mathrm{mg} / \mathrm{kg}$ ) without showing phytotoxic symptoms (Andra et al., 2009). Hundreds of plants have been identified as suitable species for phytoremediation, and a few are genetically modified to accumulate heavy metals (e.g., $\mathrm{Pb}$ ) in terms of facilitating phytoremediation (Baker and Brooks, 1989; Gisbert et al., 2003).

Although chelating agents are proved to facilitate $\mathrm{Pb}$ mobilization, the amount of applied chelating agents for phytoextraction must be optimized to avoid mobilizing excessive $\mathrm{Pb}$ from the soil, which could lead to plant toxicity and damage to the environment. However, a comprehensive analysis of the impact of EDDS dosage on $\mathrm{Pb}$ mobilization is lacking, which is crucial for the implementation of phytoremediation. The main goal of this study was to optimize the concentration of EDDS needed for $\mathrm{Pb}$ mobilization during phytoextraction in a variety of soil types, and facilitate quick and inexpensive monitoring of soil $\mathrm{Pb}$ levels in the field. In specific, the first objective of this study was to explore the impact of various EDDS concentrations on the transformation of $\mathrm{Pb}$ geochemical fractions in $\mathrm{Pb}$ paint-contaminated soils collected from three residential properties each in Jersey City, New Jersey, and San Antonio, Texas. The second objective was to correlate soil $\mathrm{Pb}$ concentration values obtained using a portable X-ray fluorescence spectrometer on-site to those obtained by Inductively Coupled Plasma-Optical Emission
Spectroscopy (ICP-OES) measurements after acid digestion of the soils.

\section{MATERIALS AND METHODS}

\section{Residential Soil Sampling and Characterization}

Representative soil samples were collected from the yards of $3 \mathrm{~Pb}$ paint contaminated homes from Jersey City and another three homes from San Antonio. Surface soil samples (0-6 inches) were collected using grid sampling. Owning to the sizes of yards, 12 samples were collected from each of the homes in Jersey City, whereas 44, 50, and 54 samples were collected from the three homesites in San Antonio.

In the laboratory, soil samples were air-dried and passed through a $2 \mathrm{~mm}$ sieve before characterization. $\mathrm{Pb}$ concentrations in all soil samples were measured and recorded on-site, using a portable X-ray Fluorescence Analyzer (p-XRF, Thermo Fisher Scientific, Niton XL3t) and in the laboratory using Inductively Coupled Plasma-Optical Emission Spectroscopy (ICP-OES, Agilent Technologies 5100) after acid digestion following USEPA Method 3050B (USEPA, 1996). Afterwards, the soil samples collected from individual houses were combined to make a composite soil sample for other analysis and EDDS extraction tests. Total concentrations of major metals ( $\mathrm{Al}, \mathrm{Fe}, \mathrm{As}, \mathrm{Cu}, \mathrm{Zn}, \mathrm{Cr}$, $\mathrm{Cd}$, and $\mathrm{Ni}$ ) were determined by ICP-OES after the acid digestion. The $\mathrm{pH}$ and electrical conductivity (EC) of soil samples were assayed using standard protocols described in Sparks et al. (2020), and the organic matter content in samples was determined using the loss on ignition (LOI) method described in Schulte and Hopkins (1996). All extractions and analyses were done in triplicate. The Quality Assurance/Quality Control protocols in Soil Sampling Quality Assurance User's Guide (Barth et al., 1989) and Acid Digestion of Sediments, Sludges, and Soils (USEPA, 1996) were followed for soil sampling and analysis in this study.

\section{Soil Pb Extraction by EDDS}

To optimize the concentration of EDDS needed to solubilize the bound $\mathrm{Pb}$ to plant-available forms, EDDS solution at different concentrations (i.e., 2, 5, 10, 15, 20, and 30 $\mathrm{mmol} / \mathrm{L}$ ) was applied to $1 \mathrm{~g}$ of a dried composite soil sample from each site. Plant-available forms of $\mathrm{Pb}$, which were water-soluble and exchangeable $\mathrm{Pb}$, were quantified after EDDS application.

\section{Geochemical Fractions of Soil Pb}

Sequential extraction of $\mathrm{Pb}$ contaminated soil (composite soil samples) before and after EDDS treatment was done using Tessier et al. (1979) method with a few modifications. Six geochemical fractions of $\mathrm{Pb}$ (i.e., water-soluble $\mathrm{F}-1$, exchangeable F-2, carbonate bound F-3, oxides bound F-4, organic bound F-5, and residual silicate bound F-6) in soil samples were determined.

EDDS extractions were done using 2 and $30 \mathrm{mmol} / \mathrm{L}$ solutions. Soil samples before and after EDDS extraction were subjected to sequential extraction. Briefly, (1) $1 \mathrm{~g}$ oven-dried soil sample was diluted with $15 \mathrm{~mL}$ deionized water, shaken at $250 \mathrm{rpm}$ for 
$2 \mathrm{~h}$, and centrifuged at $3,500 \mathrm{~g}$ for 30 minutes to obtain the F-1 fraction. (2) The residual soil was extracted using $8 \mathrm{~mL}$ of $1 \mathrm{M}$ $\mathrm{MgCl}_{2}$ for 1 hour at room temperature for the exchangeable $\mathrm{Pb}$ fraction (F-2). (3) Extraction of the F-3 fraction from the residual soil from step 2 was done using $8 \mathrm{~mL}$ of $1 \mathrm{M} \mathrm{CH}_{3} \mathrm{COONa}$ at $\mathrm{pH}$ 5.0 (adjusted using $\mathrm{CH}_{3} \mathrm{COOH}$ ) for $5 \mathrm{~h}$. (4) The oxide-bound $\mathrm{Pb}$ (fraction F-4) was extracted from the residual soil obtained from the previous step with $20 \mathrm{~mL}$ of $0.04 \mathrm{M} \mathrm{NH}_{2} \mathrm{OH} \cdot \mathrm{HCl}$ in $25 \%(\mathrm{v} / \mathrm{v})$ $\mathrm{CH}_{3} \mathrm{COOH}$ at $96^{\circ} \mathrm{C}$ for $6 \mathrm{~h}$. (5) To extract the organic bound $\mathrm{Pb}$ (fraction F-5), $3 \mathrm{~mL}$ of $0.02 \mathrm{M} \mathrm{HNO}_{3}$ and $8 \mathrm{~mL}$ of $30 \% \mathrm{H}_{2} \mathrm{O}_{2}(\mathrm{pH}$ 2.0, adjusted with $\mathrm{HNO}_{3}$ ) were added to the soil from step 4 and the samples were incubated at $85^{\circ} \mathrm{C}$ for $5 \mathrm{~h}$. After cooling, $5 \mathrm{~mL}$ of $3.2 \mathrm{M} \mathrm{CH}_{3} \mathrm{COONH}_{4}$ in $20 \%$ (v/v) $\mathrm{HNO}_{3}$ was added. (6) The residual silicate bound $\mathrm{Pb}(\mathrm{F}-6)$ was then obtained by digestion of the residual soil sample from step 5 with concentrated $\mathrm{HNO}_{3}$ at $105^{\circ} \mathrm{C}$. After each step, the supernatant was analyzed for $\mathrm{Pb}$ using ICP-OES. The soil samples from each step were weighed and used for the next step in the sequential extraction procedure.

\section{Statistical Analysis}

The data were statistically analyzed using the JMP statistical software package (JMP 14, SAS Institute Inc.). A Tukey-Kramer HSD test was used to test whether group mean pairs were significantly different at $\alpha=0.05$.

\section{RESULTS AND DISCUSSION}

\section{Chemical Properties of the Soil Samples}

The chemical properties of the soil samples collected from lead paint-contaminated homes in Jersey City and San Antonio are shown in Table 1. The Jersey City soils were slightly acidic with $\mathrm{pH}$ values ranging from 5.32 to 6.14, while the San Antonio soils were slightly alkaline with $\mathrm{pH}$ values ranging from 7.48 to 7.74. San Antonio soils contained more salts (indicated by higher EC values) and slightly more organic matter compared to Jersey City soil. Total Al and Fe concentrations are shown in Table 1. Since the concentrations of other metals (e.g., As, Cu, Zn, Cr, Cd, and $\mathrm{Ni}$, listed in Supplementary Material) were much lower than $\mathrm{Fe}$ and $\mathrm{Al}$, we primarily considered the effects of $\mathrm{Al}$ and $\mathrm{Fe}$ on $\mathrm{Pb}$ fractionation in this study. San Antonio soils had higher levels of $\mathrm{Al}$ compared to Fe, whereas the Jersey City soils had higher levels of Fe compared to Al. Figure 1 shows that the overall $\mathrm{Pb}$ concentrations in Jersey City soil were lower than those of San Antonio soils. The maximum detected $\mathrm{Pb}$ concentration in Jersey City soil was 2,696 mg/kg, while that value for San Antonio soil was $14,721 \mathrm{mg} / \mathrm{kg}$. Pb concentrations in soil samples varied spatially in each yard but showed a generally declining trend with increasing distance from the wall (Figure 2). This $\mathrm{Pb}$ distribution trend suggested that the major source of $\mathrm{Pb}$ in residential soil was from the exterior Pb-based paint (Litt et al., 2002; Clark and Knudsen, 2013), and more Pb was accumulated in the soil that was close to the residential wall after the deterioration of the paint.

\section{Evaluation of In Situ Pb Measurements by p-XRF}

The performance of $\mathrm{p}$-XRF for in situ soil $\mathrm{Pb}$ measurement was evaluated by comparing $\mathrm{p}$-XRF data with ICP-OES data. The average $\mathrm{Pb}$ concentrations of triplicated samples measured by both methods are shown in Figure 3. Strong positive correlations are indicated by $\mathrm{R}^{2}$ ranging from 0.81 to 0.97 for Jersey City soil and from 0.93 to 0.94 for San Antonio soil. These $\mathrm{R}^{2}$ values were consistent and show a better correlation compared to the reported value of 0.89 in Maliki et al. (2017). Previous studies have used $\mathrm{p}$-XRF analysis to assess metal contamination in a variety of soils. Reports indicate that the accuracy of $\mathrm{p}$-XRF measurements is variable, based on soil moisture, organic matter content, the source of the metals, as well as the types of metals being analyzed (Caporale et al., 2018; Ravansari et al., 2020). Moreover, Caporale et al. (2018) showed that the regression fits of the $\mathrm{p}$-XRF data to those obtained after extraction and mass spectrometric analysis are site-specific, and hence prediction models need to be developed for soil samples from a particular site. In the current study, the fittings for all sites showed good correlations, except for JC1 which had a relatively lower $\mathrm{R}^{2}$ at 0.81 , indicating the differences in soil properties between Jersey City and San Antonio did not significantly affect the accuracy of $\mathrm{p}$-XRF measurements. The regression slops for four of those sites (i.e., JC3, SA1, SA2, and SA3) were similar at around 0.8 , and a better correlation at JC2 showed a slope of 1.1. Thus, our data show that $\mathrm{p}$-XRF is a useful tool for rapid on-site measurements for field studies.

\section{Evaluation of EDDS Dosage on $\mathrm{Pb}$ Solubilization}

The plant-available form of $\mathrm{Pb}$ in the soil is the key and limiting factor to facilitate phytoextraction. Using vetiver grass as an example, with a massive root system, it was reported to accumulate $\mathrm{Pb}$ in root at approximately $20,000 \mathrm{mg} / \mathrm{kg}$ dry weight without showing phytotoxic symptoms in hydroponic systems (Chen et al., 2012). However, when planted in Pb-contaminated soil, the average $\mathrm{Pb}$ accumulation in vetiver grass root was reported to be below $60 \mathrm{mg} / \mathrm{kg}$ (Attinti et al., 2017). Attinti et al., 2017 found the solubility of $\mathrm{Pb}$ in soil could be enhanced by the addition of EDDS, and the accumulation of $\mathrm{Pb}$ in vetiver grass root increased by over $70 \%$. Thus, the transformation of $\mathrm{Pb}$ from bound forms to plant-available forms (i.e., water-soluble form F-1 and exchangeable form F-2) after EDDS treatment could be employed to evaluate the potentials of EDDS in enhancing phytoextraction of $\mathrm{Pb}$.

Figure 4 shows that the plant-available forms of $\mathrm{Pb}$ consisted of 0.5 to $3.9 \%$ of the total $\mathrm{Pb}$ in composite Jersey City soil samples. After extracting with EDDS at $2 \mathrm{mmol} / \mathrm{L}$, there was a large increase in plant-available $\mathrm{Pb}$ that ranged from 21.9 to $34.2 \%$. Although the ratios of plant-available $\mathrm{Pb}$ increased with increasing EDDS concentrations $(2 \mathrm{mmol} / \mathrm{L}$ to $30 \mathrm{mmol} / \mathrm{L}$ ), the plant-available $\mathrm{Pb}$ levels mobilized when the soils were treated with EDDS concentrations below 20 $\mathrm{mmol} / \mathrm{L}$ were much lower than at $20 \mathrm{mmol} / \mathrm{L}$. Significant 
TABLE 1 | Chemical properties of the residential soil (composite soil samples) in Jersey City (NJ) and San Antonio (TX).

\begin{tabular}{|c|c|c|c|c|c|c|}
\hline \multicolumn{2}{|c|}{ Sample ID } & \multirow{2}{*}{$\begin{array}{c}\mathbf{p H} \\
5.32 \pm 0.06\end{array}$} & \multirow{2}{*}{$\begin{array}{l}\text { Electrical conductivity }(\boldsymbol{\mu} \mathbf{S} / \mathbf{c m}) \\
\qquad 261 \pm 23\end{array}$} & \multirow{2}{*}{$\begin{array}{l}\text { Organic matter (\%) } \\
\qquad 9.37 \pm 0.41\end{array}$} & \multirow{2}{*}{$\begin{array}{c}\text { Total Al (mg/kg) } \\
8,784 \pm 393\end{array}$} & \multirow{2}{*}{$\frac{\text { Total Fe } \mathbf{( m g / k g )}}{11,911 \pm 1,513}$} \\
\hline Jersey City & JC1 & & & & & \\
\hline & JC2 & $6.14 \pm 0.03$ & $329 \pm 3.0$ & $10.3 \pm 0.47$ & $8,444 \pm 158$ & $15,355 \pm 1,306$ \\
\hline \multirow[t]{2}{*}{ San Antonio } & SA1 & $7.48 \pm 0.12$ & $965 \pm 12$ & $9.16 \pm 0.27$ & $18,266 \pm 402$ & $13,298 \pm 510$ \\
\hline & $\mathrm{SA} 2$ & $7.58 \pm 0.00$ & $632 \pm 4.0$ & $11.6 \pm 0.18$ & $15,929 \pm 228$ & $11,469 \pm 193$ \\
\hline
\end{tabular}

The values are shown in mean and standard deviation $(n=3)$.
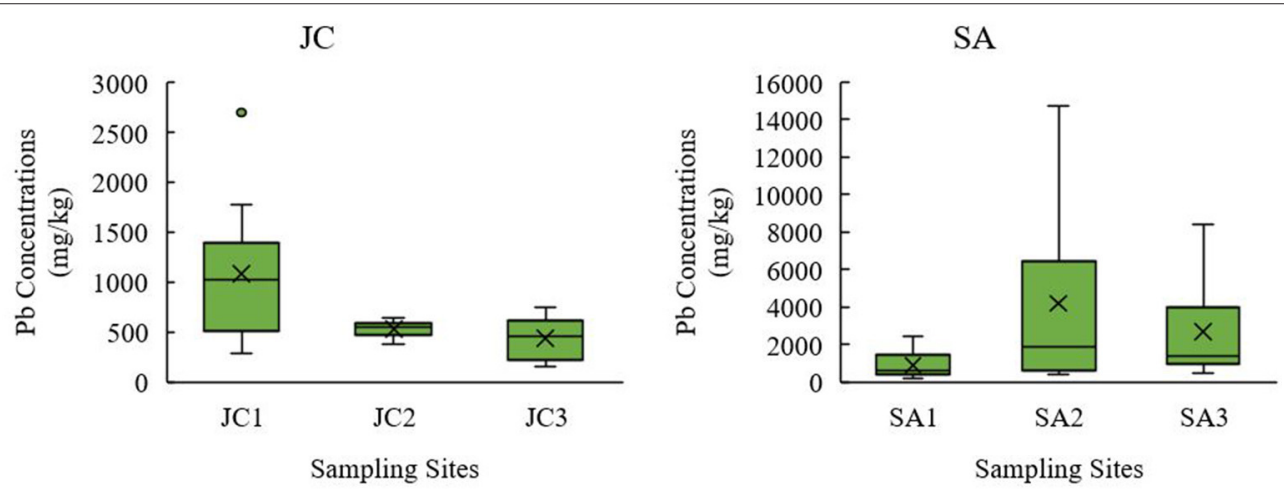

FIGURE 1 | Total Pb concentrations in three residential yards in Jersey City (JC) and three residential yards in San Antonio (SA). The cross indicates the mean value and the solid line in the box indicates the median value of the data set.
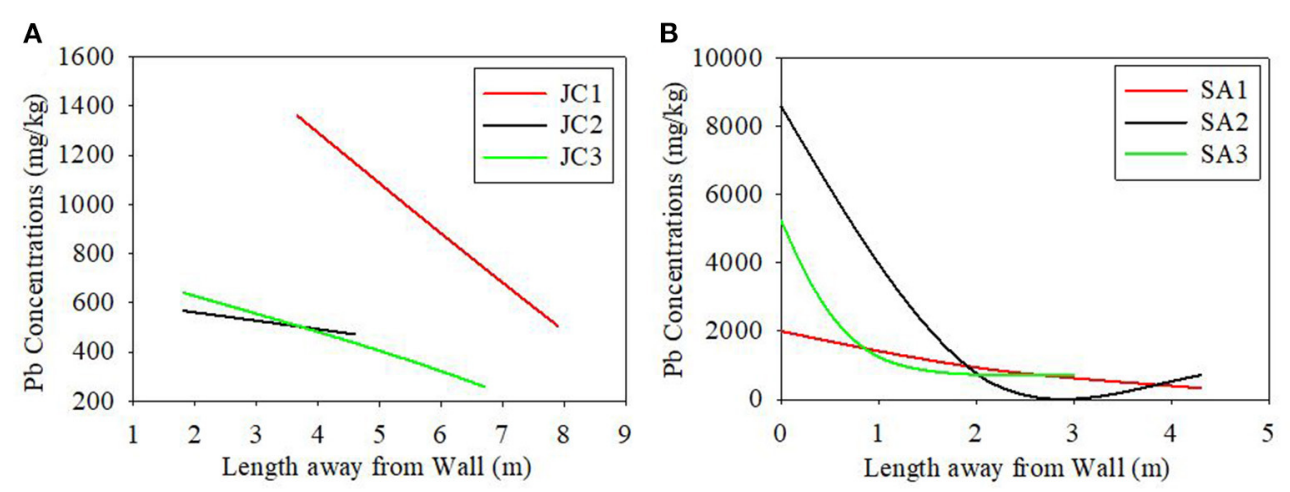

FIGURE 2 | Average soil Pb concentrations corresponding to lengths away from walls in (A) Jersey City and (B) San Antonio. The non-zero starting lengths in (A) Jersey City are due to concrete pavement next to the wall.

differences were also seen at $30 \mathrm{mmol} / \mathrm{L}$ EDDS extraction compared to that of $20 \mathrm{mmol} / \mathrm{L}$. The maximum plant-available $\mathrm{Pb}$ mobilized after EDDS treatment accounted for 44.8 to $61.2 \%$, depending on the location, after EDDS extraction at $30 \mathrm{mmol} / \mathrm{L}$.

Compared to the Jersey City soils, lower plant-available $\mathrm{Pb}$ concentrations were observed in San Antonio soils, ranging from only 0.1 to $1.4 \%$ without EDDS extraction (Figure 4). After extraction using $2 \mathrm{mmol} / \mathrm{L}$ EDDS, a $36 \%$ increase in plantavailable $\mathrm{Pb}$ was observed (Figure 4). Higher concentrations of EDDS increased the average percentages of plant-available $\mathrm{Pb}$ over total $\mathrm{Pb}$ in soil; however, in contrast to Jersey City soils, there were generally no significant differences in $\mathrm{Pb}$ mobilization beyond $10 \mathrm{mmol} / \mathrm{L}$ EDDS concentrations. With EDDS extraction in this study, up to $68.9 \%$ of total $\mathrm{Pb}$ in San Antonio soil samples was converted to plant-available forms. The increasing trend in 

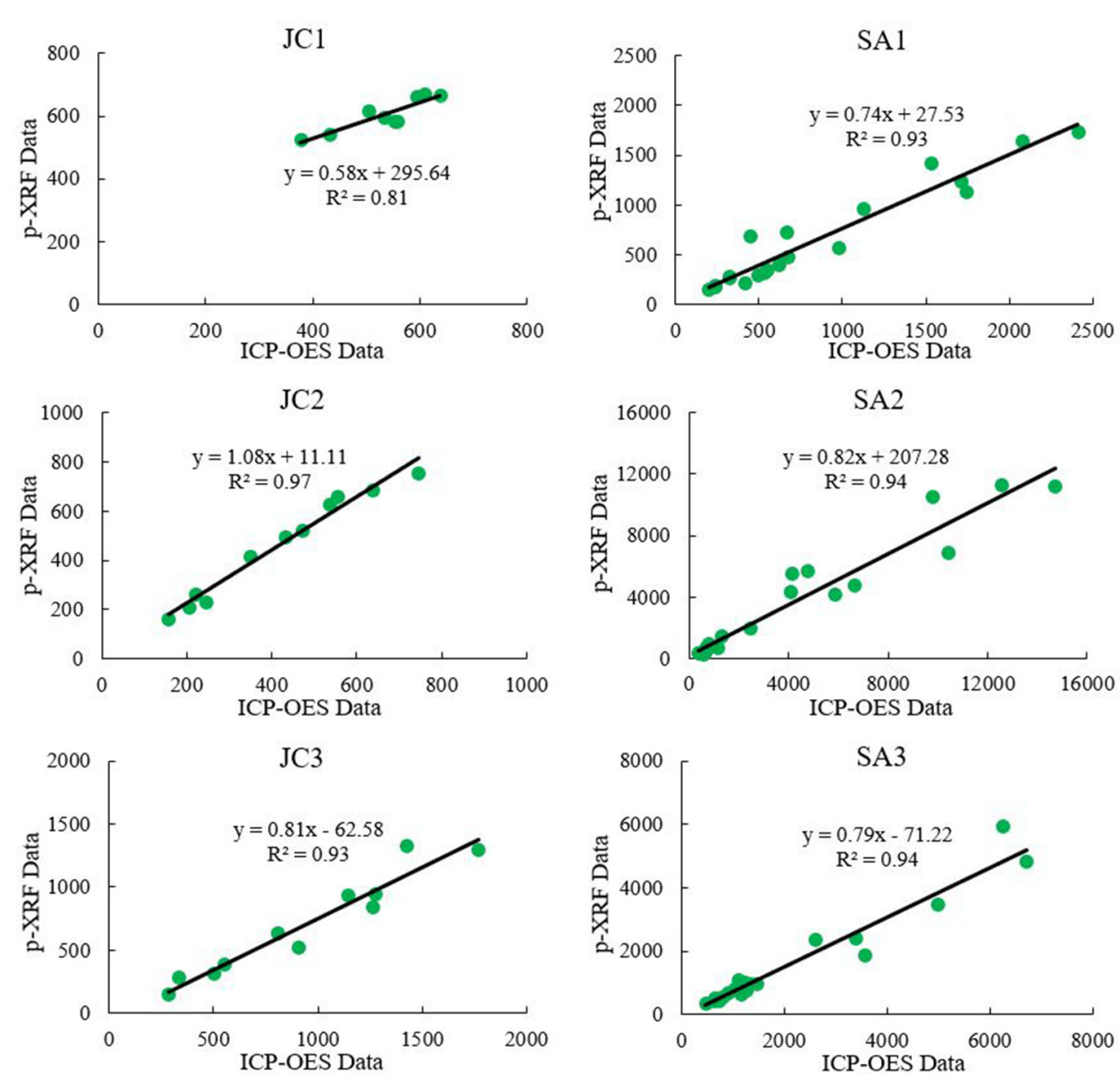

FIGURE 3 | Simple linear regression of soil Pb concentrations ( $\mathrm{mg} / \mathrm{kg}$ ) measured by p-XRF against ICP-OES in residential soils (non-composite soil samples) collected from three residential properties in Jersey City (JC1, JC2, and JC3) and three residential properties in San Antonio (SA1, SA2, and SA3).

mobilized $\mathrm{Pb}$ in Figure 4 with increasing concentrations of the chelating agent is consistent with literature that used chelating agents in $\mathrm{Pb}$ remobilization (Soltan, 2006).

Higher levels of plant-available forms of $\mathrm{Pb}$ in soil from Jersey City compared to those of San Antonio soils may be explained by the difference in soil $\mathrm{pH}$ values. Generally, the mobility and bioavailability of $\mathrm{Pb}$ increase with the decrease of pH (Kushwaha et al., 2018). Sauve et al. (1998) reported a strong negative correlation between dissolved $\mathrm{Pb}$ concentrations and $\mathrm{pH}$ under acidic conditions, and a near-constant and lowest concentration of dissolved $\mathrm{Pb}$ was shown for $\mathrm{pH}$ values between 7 and 8. Lower soil $\mathrm{pH}$ may also facilitate the conversion of other forms of $\mathrm{Pb}$, such as carbonate bound $\mathrm{Pb}$ to soluble forms (Schock, 1980), which enhanced the fraction of plantavailable $\mathrm{Pb}$ in Jersey City soil samples (Kushwaha et al., 2018). The $\mathrm{pH}$ differences between Jersey City and San Antonio soil samples could also explain the trends for the conversion of $\mathrm{Pb}$ forms; the plant-available $\mathrm{Pb}$ ratios for Jersey City soil did not change much at lower EDDS concentrations ranging from 2 to $10 \mathrm{mmol} / \mathrm{L}$, while those ratios increased significantly for San Antonio soil. This could be explained by better $\mathrm{Pb}$ extraction performance by EDDS under alkaline conditions, especially when there was an EDDS deficiency situation (Yan et al., 2010).

\section{Changes in Pb Geochemical Forms After EDDS Addition}

By tracking the changes in the bound forms of $\mathrm{Pb}$ in Jersey City and San Antonio soils using sequential extraction before and after EDDS treatment, the impact of EDDS in mobilizing the various fractions of soil $\mathrm{Pb}$ could be estimated. For this experiment, EDDS treatment was performed at $2 \mathrm{mmol} / \mathrm{L}$ and 30 $\mathrm{mmol} / \mathrm{L}$ concentrations. In general, a decreasing trend was seen in the various $\mathrm{Pb}$ fractions after EDDS treatment, in particular in the F-3, F-5, and F-6 fractions (Figure 5). Lead in F-1 and F-2 fractions were negligible for all soil samples before EDDS treatment, which corresponds to the low plant-available $\mathrm{Pb}$ seen in Figure 4. The majority of $\mathrm{Pb}$ existed in the residual silicate bound form (F-6), indicating that most of the $\mathrm{Pb}$ were recalcitrant with low solubility, which would be difficult to remediate (Elless et al., 2007). Compared to the Jersey City soil samples, there was 

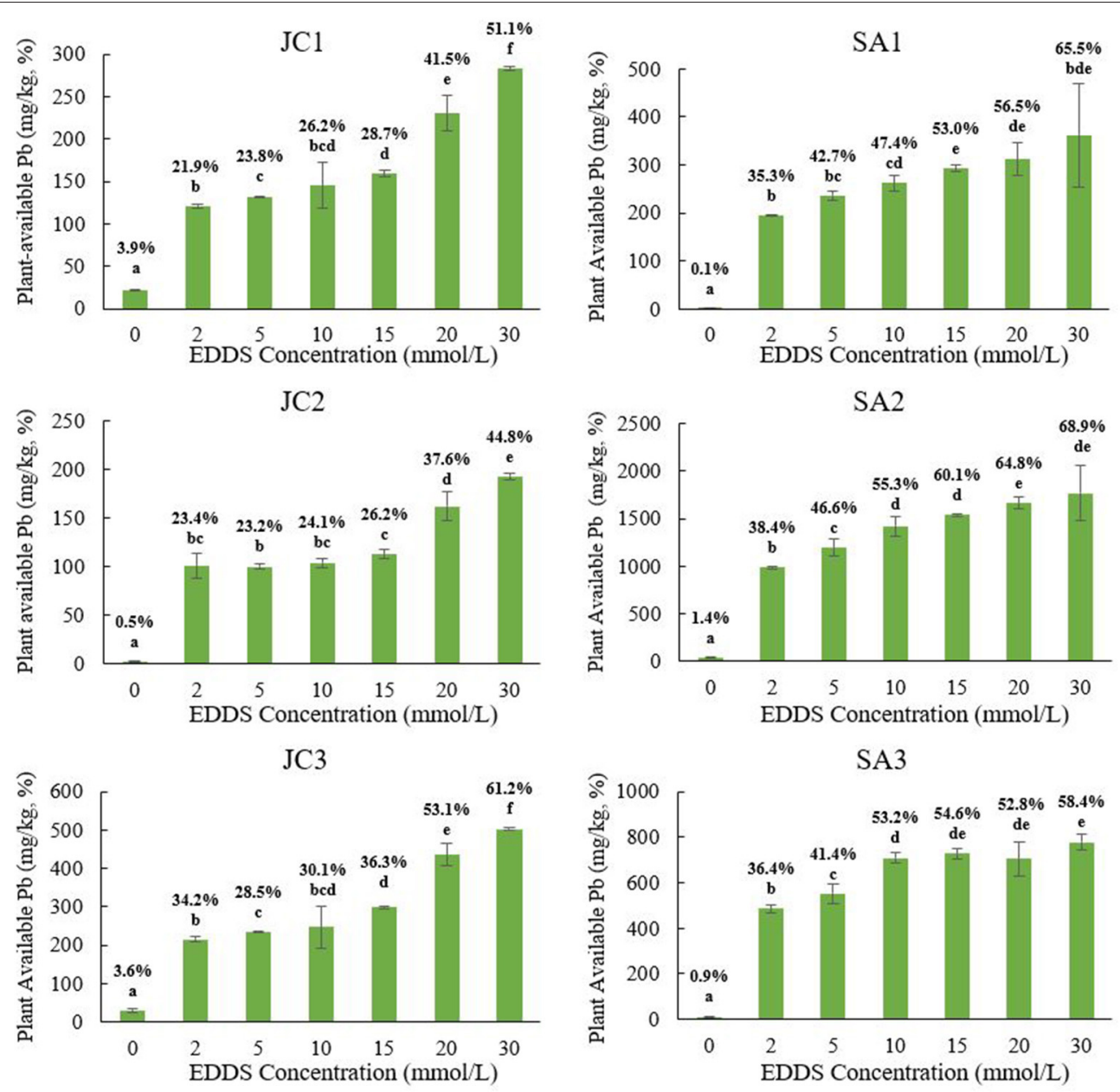

FIGURE 4 | Conversion of bound Pb to plant-available Pb forms at various EDDS concentrations in residential soils (composite soil samples, $n=3$ ) collected from three residential properties in Jersey City (JC1, JC2, and JC3) and three residential properties in San Antonio (SA1, SA2, and SA3). Results are shown in both actual plant available $\mathrm{Pb}$ concentrations and ratios of plant available $\mathrm{Pb}$ to total $\mathrm{Pb}$ in the samples. Different letters in the same plot correspond to statistically significant differences $(P<0.05)$

more $\mathrm{Pb}$ within the F-3 and F-5 fractions of the San Antonio soil samples, which can be explained by the higher $\mathrm{pH}$ and the higher organic matter content in these soils respectively (Table 1).

Soil $\mathrm{Pb}$ mobilization by chelating agents such as EDTA and EDDS has been previously reported. In both acidic and alkaline soil conditions, chelating agents have been reported to primarily reduce organic-bound $\mathrm{Pb}(\mathrm{F}-5)$ among all $\mathrm{Pb}$ fractions while enhancing the water-soluble and exchangeable $\mathrm{Pb}$ fractions ( $\mathrm{Li}$ et al., 2005; Yan et al., 2010; Chen et al., 2012). Li et al. (2005) also indicated a decline in oxide-bound $\mathrm{Pb}(\mathrm{F}-4)$ and residual silicate bound $\mathrm{Pb}(\mathrm{F}-6) \mathrm{Pb}$ fractions using EDTA as the chelating agent. Our results show that while the $\mathrm{Pb}$ in the $\mathrm{F}-4$ fraction increased with the $2 \mathrm{mmol} / \mathrm{L}$ EDDS treatment, at the higher dose of 30 $\mathrm{mmol} / \mathrm{L}$, there was a decrease in $\mathrm{Pb}$ concentration in the same fraction. It is likely that with EDDS application at $2 \mathrm{mmol} / \mathrm{L}$, the dissolution of certain compounds (e.g., organic matter) induced by EDDS released $\mathrm{Pb}$ which could then be re-adsorbed to the metal oxides, leading to the increase in $\mathrm{F}-4$ bound $\mathrm{Pb}$ (Figure 5).
This assumption is further supported by the presence of high concentrations of $\mathrm{Fe}$ and $\mathrm{Al}$ in soil samples from both Jersey City and San Antonio, which can induce Pb-binding (Table 1) (Yan et al., 2010). Cao et al. (2008) illustrated that higher EDDS dosage $(10 \mathrm{~mol}$ EDDS: $1 \mathrm{~mol} \mathrm{~Pb})$ could reduce ratios of metal oxides bound $\mathrm{Pb}$ compared to low dosage (1 mol EDDS: $1 \mathrm{~mol}$ $\mathrm{Pb}$ ), which may explain the decrease in the F-4 fraction after EDDS application at $30 \mathrm{mmol} / \mathrm{L}$.

The silicate-bound $\mathrm{Pb}$ fraction (F-6) has been reported as the most difficult fraction to mobilize, while other $\mathrm{Pb}$ fractions (i.e., F-3, F-4, and F-5) could be transformed into plant-available forms. However, our results show that that $56.1-77.0 \%$ of the $\mathrm{Pb}$ in the F-6 fraction was mobilized by $30 \mathrm{mmol} / \mathrm{L} \mathrm{Pb}$ in Jersey City soils, while the percentages for San Antonio soils were 67.2$86.8 \%$ (Figure 5). Since the $\mathrm{Pb}$ concentration in the F-6 fraction generally decreased with an increase in EDDS concentrations as shown in Figure 5, the above percentages could be even higher if the EDDS concentration is further increased. However, in real-world applications, mobilization of $\mathrm{Pb}$ needs to be balanced 

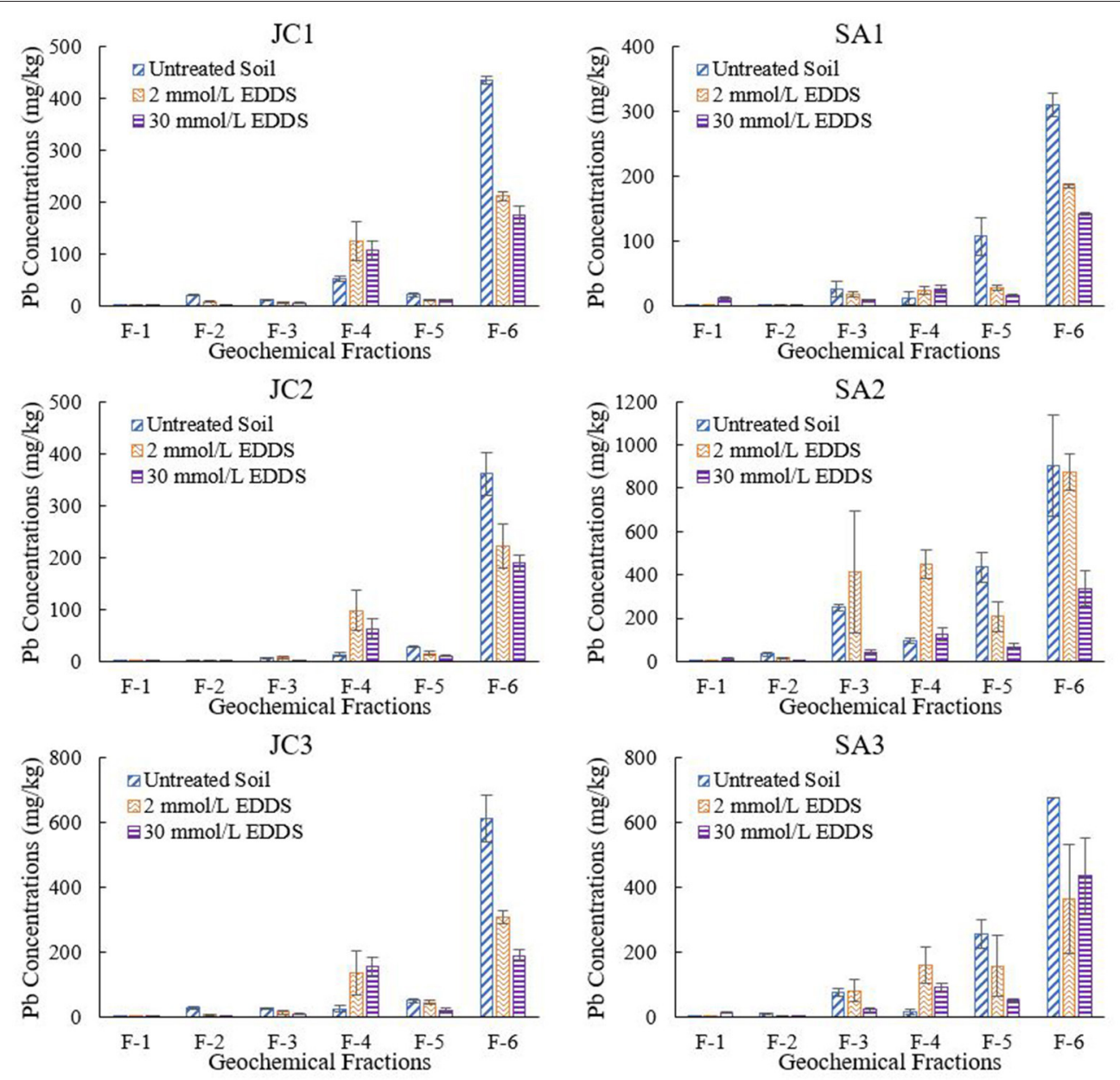

FIGURE 5 | Geochemical fractions of Pb obtained by sequential extraction before and after EDDS extraction in residential soils (composite soil samples, $n=3$ ) collected from three residential properties in Jersey City (JC1, JC2, and JC3) and three residential properties in San Antonio (SA1, SA2, and SA3). F-1: water-soluble $\mathrm{Pb}$; F-2: exchangeable Pb; F-3: carbonate-bound Pb; F-4: oxide-bound Pb; F-5: organic-bound Pb; F-6: silicate-bound Pb.

with plant uptake to prevent the leaching of $\mathrm{Pb}$ into surface and groundwater. An alternative would be to use a coated chelating agent, which slows down its release. In doing so, $\mathrm{Pb}$ mobilization could be balanced by plant uptake during phytoremediation ( $\mathrm{Li}$ et al., 2005).

\section{CONCLUSION}

A soil survey of three $\mathrm{Pb}$-contaminated homes each in Jersey City and San Antonio showed that the $\mathrm{Pb}$ concentrations in composite soil samples were all above the USEPA soil Pb hazard cutoff value of $400 \mathrm{mg} / \mathrm{kg}$. Comparison of the $\mathrm{Pb}$ data obtained in-situ using a p-XRF instrument was compatible with those obtained after acid digestion and ICP-OES analysis in the lab. Hence, for our ongoing field studies, $\mathrm{p}$-XRF would provide a rapid, convenient and inexpensive method to track $\mathrm{Pb}$ levels in the soil. The impact of a biodegradable chelating agent EDDS on $\mathrm{Pb}$ mobilization in soils was assessed in this study. Higher doses of EDDS induced more bound $\mathrm{Pb}$ fractions to be converted to plant-available $\mathrm{Pb}$ forms. For EDDS application at $30 \mathrm{mmol} / \mathrm{L}$, up to $68.9 \%$ of the total $\mathrm{Pb}$ became plant-available. Further analysis on how EDDS changed the fractions of existing $\mathrm{Pb}$ forms illustrated that bound $\mathrm{Pb}$ forms were converted to plant-available $\mathrm{Pb}$ at various ratios. In addition to being effective in mobilizing $\mathrm{Pb}$, EDDS is biodegradable with a short half-life in soil, which makes it an attractive option for phytoremediation projects. A field study is currently in progress at the three residential sites using the chemically-catalyzed phytoextraction regime optimized in this study.

\section{DATA AVAILABILITY STATEMENT}

Data presented in this study are available on request from the corresponding author.

\section{AUTHOR CONTRIBUTIONS}

DS and RD conceptualized and designed the study and obtained the funding. ZZ, VS, and MW performed the field 
studies and sample analysis. ZZ and VS wrote the first draft of the paper. RD and DS reviewed and edited the paper. All authors contributed to the article and approved the submitted version.

\section{FUNDING}

This work was supported by a Lead Technical Studies grant (\#MILTS0007-17) from the U.S. Housing and Urban Development Grant.

\section{REFERENCES}

Alkorta, I., Hernández-Allica, J., Becerril, J. M., Amezaga, I., Albizu, I., and Garbisu, C. (2004a). Recent findings on the phytoremediation of soils contaminated with environmentally toxic heavy metals and metalloids such as zinc, cadmium, lead, and arsenic. Rev Environ Sci Bio. 3, 71-90. doi: 10.1023/B:RESB.0000040059.70899.3d

Alkorta, I., Hernández-Allica, J., Becerril, J. M., Amezaga, I., Albizu, I., Onaindia, M., et al., (2004b). Chelate-enhanced phytoremediation of soils polluted with heavy metals. Rev Environ Sci Bio. 3, 55-70. doi: 10.1023/B:RESB.0000040057.45006.34

Andra, S. S., Datta, R., Sarkar, D., Makris, K. C., Mullens, C. P., Sahi, S. V., et al., (2009). Induction of lead-binding phytochelatins in vetiver grass [Vetiveria zizanioides (L.)]. J. Environ. Qual. 38, 868-877. doi: 10.2134/jeq2008.0316

Attinti, R., Barrett, K. R., Datta, R., and Sarkar, D. (2017). Ethylenediaminedisuccinic acid (EDDS) enhances phytoextraction of lead by vetiver grass from contaminated residential soils in a panel study in the field. Environ. Pollut. 225, 524-533. doi: 10.1016/j.envpol.2017.01.088

Baker, A. J., and Brooks, R. (1989). Terrestrial higher plants which hyperaccumulate metallic elements - A review of their distribution, ecology and phytochemistry. Biorecovery. 1, 81-126.

Barth, D. S., Mason, B. J., Starks, T. H., and Brown, K. W. (1989). Soil Sampling Quality Assurance User's Guide, 2nd ed.; EPA/600/8-89/046; U.S. EPA: Washington, DC 1989.

Cao, A., Cappai, G., Carucci, A., and Lai, T. (2008). Heavy metal bioavailability and chelate mobilization efficiency in an assisted phytoextraction process. Environ. Geochem. Health. 30, 115-119. doi: 10.1007/s10653-008-9136-2

Caporale, A. G., Adamo, P., Capozzi, F., Langella, G., Terribile, F., and Vingiani, S. (2018). Monitoring metal pollution in soils using portable-XRF and conventional laboratory-based techniques: Evaluation of the performance and limitations according to metal properties and sources. Sci. Total Environ. 643, 516-526. doi: 10.1016/j.scitotenv.2018.06.178

Chen, K. F., Yeh, T. Y., and Lin, C. F. (2012). Phytoextraction of Cu, Zn, and Pb enhanced by chelators with vetiver (Vetiveria zizanioides): hydroponic and pot experiments. ISRN Ecology 2012:1-12. doi: 10.5402/2012/729693

Clark, J. J., and Knudsen, A. C. (2013). Extent, characterization, and sources of soil lead contamination in small-urban residential neighborhoods. J. Environ. Qual. 42, 1498-1506. doi: 10.2134/jeq2013.03.0100

Clark, S., Bornschein, R., Succop, P., Roda, S., and Peace, B. (1991). Urban lead exposures of children in Cincinnati, Ohio. Chem Speciation Bioavailabil. 3, 163-171. doi: 10.1080/09542299.1991.11083167

Elhelu, M. A., Caldwell, D. T., and Hirpassa, W. D. (1995). Lead in inner-city soil and its possible contribution to children's blood lead. Arch. Environ. Health. 50, 165-169. doi: 10.1080/00039896.1995.9940894

Elless, M. P., Bray, C. A., and Blaylock, M. J. (2007). Chemical behavior of residential lead in urban yards in the United States. Environ. Pollut. 148, 291-300. doi: 10.1016/j.envpol.2006.10.024

Gisbert, C., Ros, R., De Haro, A., Walker, D. J., Bernal, M. P., Serrano, R., et al., (2003). A plant genetically modified that accumulates $\mathrm{Pb}$ is especially promising for phytoremediation. Biochem. Biophys. Res. 303, 440-445. doi: 10.1016/S0006-291X(03)00349-8

\section{ACKNOWLEDGMENTS}

Willie Villarreal from the City of San Antonio is acknowledged for his help with collecting the samples. We gratefully acknowledge the participating homeowners in this study.

\section{SUPPLEMENTARY MATERIAL}

The Supplementary Material for this article can be found online at: https://www.frontiersin.org/articles/10.3389/frsc.2021. 773467/full\#supplementary-material

Gluhar, S., Kaurin, A., and Lestan, D. (2020). Soil washing with biodegradable chelating agents and EDTA: Technological feasibility, remediation efficiency and environmental sustainability. Chemosphere. 257, 127226. doi: 10.1016/j.chemosphere.2020.127226

Johnson, D. L., and Bretsch, J. K. (2002). Soil lead and children's blood lead levels in Syracuse, NY, USA. Environ. Geochem. Health. 24, 375-385. doi: 10.1023/A:1020500504167

Kushwaha, A., Hans, N., Kumar, S., and Rani, R. (2018). A critical review on speciation, mobilization and toxicity of lead in soil-microbe-plant system and bioremediation strategies. Ecotoxicol. Environ. Saf. 147, 1035-1045. doi: 10.1016/j.ecoenv.2017.09.049

Laidlaw, M. A., Filippelli, G. M., Brown, S., Paz-Ferreiro, J., Reichman, S. M., Netherway, P., et al., (2017). Case studies and evidence-based approaches to addressing urban soil lead contamination. Appl. Geochem. 83, 14-30. doi: 10.1016/j.apgeochem.2017.02.015

Li, H., Wang, Q., Cui, Y., Dong, Y., and Christie, P. (2005). Slow release chelate enhancement of lead phytoextraction by corn (Zea mays L.) from contaminated soil - A preliminary study. Sci. Total Environ. 339, 179-187. doi: 10.1016/j.scitotenv.2004.07.020

Li, H. B., Yu, S., Li, G. L., and Deng, H. (2012). Lead contamination and source in Shanghai in the past century using dated sediment cores from urban park lakes. Chemosphere. 88, 1161-1169. doi: 10.1016/j.chemosphere.2012.03.061

Litt, J. S., Hynes, P., Carroll, P., Maxfield, R., McLaine, P., and Kawecki, C. (2002). Safe yards: Improving urban health through lead-safe yards. J. Urban Technol. 9, 71-93. doi: 10.1080/1063073022000016487

Maliki, A., Al-lami, A. K., Hussain, H. M., and Al-Ansari, N. (2017). Comparison between inductively coupled plasma and X-ray fluorescence performance for $\mathrm{Pb}$ analysis in environmental soil samples. Environ. Earth Sci. 76, 433. doi: 10.1007/s12665-017-6753-z

McClintock, N. (2012). Assessing soil lead contamination at multiple scales in Oakland, California: Implications for urban agriculture and environmental justice. Appl. Geogr. 35, 460-473. doi: 10.1016/j.apgeog.2012.10.001

Mielke, H. W., Anderson, J. C., Berry, K. J., Mielke, P. W., Chaney, R. L., and Leech, M. (1983). Lead concentrations in inner-city soils as a factor in the child lead problem. Am. J Public Health 73, 1366-1369. doi: 10.2105/AJPH.73.12.1366

Mielke, H. W., Dugas, D., Mielke Jr, P. W., Smith, K. S., and Gonzales, C. R. (1997). Associations between soil lead and childhood blood lead in urban New Orleans and rural Lafourche Parish of Louisiana. Environ. Health Perspect. 105, 950-954. doi: 10.1289/ehp.97105950

Mielke, H. W., Gonzales, C. R., Powell, E. T., Laidlaw, M. A., Berry, K. J., Mielke, P. W., et al., (2019). The concurrent decline of soil lead and children's blood lead in New Orleans. Proc. Natl. Acad. Sci. U.S.A. 116, 22058-22064. doi: 10.1073/pnas.1906092116

Mojiri, A. (2011). The potential of corn (Zea mays) for phytoremediation of soil contaminated with cadmium and lead. J. Biol. Environ. Sci. 5, 17-22.

Ravansari, R., Wilson, S. C., and Tighe, M. (2020). Portable X-ray fluorescence for environmental assessment of soils: Not just a point and shoot method. Environ. Int. 134, 105250. doi: 10.1016/j.envint.2019.105250

Sauve, S., McBride, M., and Hendershot, W. (1998). Soil solution speciation of lead (II): Effects of organic matter and pH. Soil Sci. Soc. Am. J. 62, 618-621. doi: 10.2136/sssaj1998.03615995006200030010x 
Schock, M. R. (1980). Response of lead solubility to dissolved carbonate in drinking water. J. Am. Water Work. Assoc. 72, 695-704. doi: 10.1002/j.1551-8833.1980.tb04616.x

Schulte, E. E., and Hopkins, B. G. (1996). Estimation of soil organic matter by weight loss-on-ignition. SSSA Special Publication. Soil Organic Matter: Analysis and Interpretation, eds Magdoff, F. R., Tabatabai, M. A., \& Hanlon E. A. (USA: Soil Science Society of America). pp. 21-31. doi: 10.2136/sssaspecpub46.c3

Soltan, M. E. (2006). Remobilization of selected metal ions from Nile sediment (Egypt) according to sequential extraction and metal-EDTA complex. Chem Ecol. 22, 359-378. doi: 10.1080/02757540600917468

Sparks, D. L., Page, A. L., Helmke, P. A., and Loeppert, R. H. (Eds.). (2020). Methods of soil analysis, part 3: Chemical methods, Vol. 14. Madison, WI: John Wiley \& Sons.

Tessier, A., Campbell, P. G., and Bisson, M. J. A. C. (1979). Sequential extraction procedure for the speciation of particulate trace metals. Anal. Chem. 51, 844-851. doi: 10.1021/ac50043a017

USEPA (1996). Method 3050B: Acid Digestion of Sediments, Sludges, and Soils, Revision 2. Washington, DC.

USEPA (2001). Lead: identification of dangerous levels of lead. Final rule. Federal Register. 66, 1206-1240.

Yan, D. Y., Yip, T. C., Yui, M. M., Tsang, D. C., and Lo, I. M. (2010). Influence of EDDS-to-metal molar ratio, solution $\mathrm{pH}$, and soil-to-solution ratio on metal extraction under EDDS deficiency. J. Hazard. Mater. 178, 890-894. doi: $10.1016 /$ j.jhazmat.2010.02.021
Zahran, S., Mielke, H. W., McElmurry, S. P., Filippelli, G. M., Laidlaw, M. A., and Taylor, M. P. (2013). Determining the relative importance of soil sample locations to predict risk of child lead exposure. Environ. Int. 60, 7-14. doi: 10.1016/j.envint.2013. 07.004

Conflict of Interest: The authors declare that the research was conducted in the absence of any commercial or financial relationships that could be construed as a potential conflict of interest.

Publisher's Note: All claims expressed in this article are solely those of the authors and do not necessarily represent those of their affiliated organizations, or those of the publisher, the editors and the reviewers. Any product that may be evaluated in this article, or claim that may be made by its manufacturer, is not guaranteed or endorsed by the publisher.

Copyright (C) 2022 Zhang, Sarkar, Sidhu, Warke and Datta. This is an open-access article distributed under the terms of the Creative Commons Attribution License (CC $B Y)$. The use, distribution or reproduction in other forums is permitted, provided the original author(s) and the copyright owner(s) are credited and that the original publication in this journal is cited, in accordance with accepted academic practice. No use, distribution or reproduction is permitted which does not comply with these terms. 